\title{
Medical Cost and Motorcycle Helmet Law in Taiwan
}

\author{
Chin-Shyan Chen ${ }^{1}$ and Tsai-Ching Liu ${ }^{2}$ \\ ${ }^{1}$ Department of Economics, National Taipei University, 151 University Road, San Shia, New Taipei 237, Taiwan \\ ${ }^{2}$ Department of Public Finance, National Taipei University, 151 University Road, San Shia, New Taipei 237, Taiwan
}

Correspondence should be addressed to Chin-Shyan Chen, stan@mail.ntpu.edu.tw

Received 3 January 2012; Accepted 18 March 2012

Academic Editor: Junsen Zhang

Copyright ( 2012 C.-S. Chen and T.-C. Liu. This is an open access article distributed under the Creative Commons Attribution License, which permits unrestricted use, distribution, and reproduction in any medium, provided the original work is properly cited.

The objective of this study was to examine whether the implementation of the helmet law had reduced the likelihood of head injury and the associated medical cost in Taiwan. Data were taken from the 1996 and 1998 population-based data. In total, 888,179 and 921,058 effective samples were used in the study from the two years. Two different types of regression model were adopted to evaluate the impact of the motorcycle helmet use law on incidences of head injury and associated medical cost and hospital length of stay. The results reveal that medical cost is down by 11.5 percent and hospital LOS has fallen by 18.58 percent. Thus, with the introduction of the motorcycle helmet use law having had a demonstrably positive influence on motorcycle head injuries and fatalities, significant savings are clearly being achieved, not only in terms of economic and social costs, but also with regard to medical cost.

\section{Introduction}

The law establishing the mandatory use of motorcycle helmets in Taiwan came into force on June 1, 1997. Riding motorcycle without a helmet will be fined NT\$500 (US\$15) for each person according to Taiwan Traffic Penalty Rules. It had been previously determined that, in 1996, Taiwan had a total of 9.28 million motorcycles, as compared to 4.99 million automobiles and, according to statistics provided by Ministry of Interior, there were 2,990 traffic-related fatalities, defined as a fatality occurring at the scene of the crash or within 24 hours of the crash, that year [1]. Approximately $44 \%$ of these crashes, or about 1,330, involved motorcycles.

Numerous studies have indicated a high correlation between fatal head injuries and accidents involving motorcycles, with helmets having been shown to be extremely effective in preventing serious head injury. The enforcement of laws relating to the mandatory use of motorcycle helmets in many countries has also proven to have significantly reduced both head injuries and fatalities [2-10].

Thus far, there have been several studies carried out in Taiwan evaluating the law on the mandatory use of motorcycle helmets and the subsequent effects on both head injuries and fatalities. Using data from police accident reports,
Tsai and Hemenway (1999) [11] found that, following the implementation of the law on helmet usage, there were a reduction of 14 percent in motorcycle fatalities and an even greater reduction of 22 percent in head injury fatalities [11].

Chiu et al. (2000) [12] subsequently used data collected from 56 major teaching hospitals in Taiwan to compare motorcycle head injury cases before and after the introduction of the law mandating the use of helmets. Their results suggested that the decline in the number of motorcycle head injuries following the introduction of the law was even greater, at 33 percent, whilst both the severity of the head injuries and the average length of stay in hospital were found to have been significantly reduced [12].

Lee et al. (2010) [10] also used 3328 hospital-based samples to estimate loss of quality-adjusted life years (QALYs) among motorcyclists who suffered head injuries while wearing or not wearing a helmet. The results supported the effectiveness of helmet use in reducing an average loss of QALY. Motorcyclists with helmet use had a lower average loss of QALYs than their counterparts (5.8 versus 10.7) [10].

There have been many studies examining the motorcycle helmet law and the tendency has been to focus on reductions in injuries and fatalities using data from specific areas or hospitals. To the best of our knowledge, the association 
between the implementation of helmet use law and the likelihood of head injury and the associated medical care utilization has drawn precious little attention. Nor has any study addressed differences in such a relationship using population-based database. This study is the first of its kind worldwide to use a selected population-based data in an attempt to estimate the impact of the helmet use law on the likelihood of head injury and the associated medical utilization. If such likelihood and utilization have been effectively reduced by the implementation of the motorcycle helmet law, through a reduction in the severity of head injuries, then valuable medical resources can be used more effectively in other areas of inpatient care.

\section{Methods}

2.1. Data. The data used in this study is obtained from the Taiwan National Health Insurance Research Database (NHIRD). The NHIRD represents one of the most comprehensive population-based databases in the world, given that the National Health Insurance (NHI) system in Taiwan covers approximately 99 percent of the island's entire population. The data includes information on all inpatient and outpatient medical claims, contracted medical facilities and physicians. The Longitudinal Health Insurance database (LHID) created and released by the Taiwan National Health Research Institute consists of 1,000,000 subjects by systematically selecting a representative database from the 25.68 million enrollees listed in the 2005 Registry of Beneficiaries from NHIRD. There is no significant difference between the patients in the LHID and the NHIRD in gender distribution, age distribution, or a beneficiary's annual sum of insurance claims. Consequently, the LHID has been widely used in the health researches and policy making.

As the NHI system was implemented in Taiwan in March 1995, we are able to use this database to fully evaluate the impact of the 1997 helmet use law on medical care utilization involving head injuries. We use the LHID dataset released in 2007 as our study sample, which involved the random sampling one million NHI beneficiaries. Our sample comprises of all inpatient and outpatient medical claims one year prior to the implementation of the motorcycle helmet use law (1996) and one year after its implementation (1998).

The dataset provides primary diagnoses from the International Classification of Disease, Ninth Revision, Clinical Modification (ICD-9-CM) and up to four secondary diagnoses. After deleting some samples with missing information, we were left with a total of 888,179 and 921,058 observations of patients in 1996 and 1998, respectively. ICD9-CM codes 800-999 and E codes (external injury) 810-819 (motor vehicles) were used to identify the head injury cases, and the final dataset of head injuries for analysis in this study includes 609 and 645 cases. The definitions of the variables selected for this study are provided in Table 1.

2.2. Analytical Techniques. The analysis in this study is undertaken in two parts. Firstly, we present the sample characteristics of percentage, medical cost, and hospital length of stay attributable to motorcycle head injuries both before and after the introduction of the helmet use law. Secondly, we apply two different types of regression model to explore the influence of helmet use law on probability, medical cost, as well as length of stay. In the first type, we formulated the logistic regression to estimate the impact of helmet use law on the probability of head injury. The first type of model is as follows:

$$
\begin{aligned}
\text { head injury }{ }_{i}^{*}= & \beta_{0}+\beta_{1} G_{i}+\beta_{2} A_{i}+\beta_{3} W_{i}+\beta_{4} G E_{i} \\
& +\beta_{5} R_{i}+\beta_{6} P_{i}+\beta_{7} P_{i} \times G E_{i}+\varepsilon_{i},
\end{aligned}
$$

where $i$ refers to the individual; $\beta_{s}$ are the parameters to be estimated; $\varepsilon$ is the error term, and the remaining variables are the explanatory variables including "gender" $(G)$, "age" $(A)$, "weekday" $(W)$, "geographical location" $(G E)$, "rural area" $(R)$, "helmet use law policy" $(P)$, and $P^{*} G E$ ' interaction. The uneven distribution of resources in Taiwan has been criticized. Unlike the northern area where the majority of resources are centralized, the shortage of police to nonnorthern areas is likely to hamper the enforcement of motorcycle helmet law. Eastern region which is less developed than the other regions may be even worse. Therefore, this study included three $P^{*} G E$ interactions (Policy*Center, Policy*South, policy*East) to explore whether there was any change with regard to regional differences in the incidence of motorcycle head injuries between the two study years.

Although the head injury* variable is unobserved, we define a dummy variable, head injury ${ }_{i}$, which is observed, as follows:

$$
\text { head } \text { injury }_{i}= \begin{cases}1 & \text { if head injury } \\ 0 & \text { else. }\end{cases}
$$

The second type of estimation considers the amount of medical costs and the hospital length of stay conditional on the occurrence of head injury. Two regression analyses are undertaken in the second type, each with a specific purpose. Since the dependent variable (the amount of expenses) is a continuous variable, we adopted the ordinary least squares regression as the means of investigating whether after the implementation of helmet use law incurred lower medical expenditures than before. Using the "cost-" dependent variable, the $F$ value was not statistically significant $[\operatorname{prob}(F)=$ 0.2213 ] and the cost was not normally distributed; we used an appropriated adjustment which transferred the "cost-" dependent variable into a logarithm. After transferring cost into the logarithm, the $F$ value became statistically significant $[\operatorname{prob}(F)<0.05]$. For the analysis of the hospital length of stay, the dependent variable used in the model is a discrete variable-days of hospitalization, the count data model should be introduced in the estimation in order to capture the non-negative integer values. In the analysis of count data, 
TABLE 1: Definitions of the dependent and independent variables.

\begin{tabular}{|c|c|}
\hline Variable & \\
\hline \multicolumn{2}{|l|}{ Dependent variables } \\
\hline Probability & Traffic accident with head injury $=1$; other $=0$ \\
\hline Medical cost & NT dollars ${ }^{\mathrm{a}}$ \\
\hline Length of stay in hospital & Inpatient days \\
\hline \multicolumn{2}{|l|}{ Independent variables } \\
\hline \multirow{2}{*}{ Policy } & After motorcycle helmet use law = 1 \\
\hline & Before motorcycle helmet use law $=0$ \\
\hline \multicolumn{2}{|l|}{ Geographic location } \\
\hline North & $\begin{array}{l}\text { Patient lived in Taipei City, Keelung City, Taipei County, Yilan County, Hsinchu City, Taoyuan } \\
\text { County, Hsinchu County, and Miaoli County; yes }=1 \text {, other }=0\end{array}$ \\
\hline Center & $\begin{array}{l}\text { Patient lived in: Taichung City, Taichung County, Changhua County, and Nantou County; yes = } \\
1, \text { other }=0\end{array}$ \\
\hline South & $\begin{array}{l}\text { Patient lived in: Tainan City, Chiayi City, Yunlin County, Chiayi County, Tainan County, } \\
\text { Kaohsiung City, Kaohsiung County, Pingtung County, and Penghu County; yes = 1, other }=0\end{array}$ \\
\hline East & Patient lived in: Hualien County and Taitung County; yes $=1$, other $=0$ \\
\hline Gender & Male $=1 ;$ female $=0$ \\
\hline \multicolumn{2}{|l|}{ Age } \\
\hline Children & Patient's age from 0 to 14 years old $=1$; other $=0$ \\
\hline Adult 15-24 & Patient's age from 15 to 24 years old $=1$; other $=0$ \\
\hline Adult 25-64 & Patient's age from 25 to 64 years old $=1$; other $=0$ \\
\hline Elderly & Patient's age over 65 years old $=1$; other $=0$ \\
\hline \multicolumn{2}{|l|}{ Rural/urban ${ }^{\mathrm{b}}$} \\
\hline Special municipality & $\begin{array}{l}\text { Patient lived in special municipality (regions with populations of not less than } 1,250,000 \text { and have } \\
\text { special requirements in their political, economic, cultural, and metropolitan developments) }=1 \text {; } \\
\text { other }=0\end{array}$ \\
\hline City & $\begin{array}{l}\text { Patient lived in city (regions with populations of not less than } 500,000 \text { but not more than } \\
1,250,000 \text { and occupy major political, economic, and cultural roles) }=1 \text {; other }=0\end{array}$ \\
\hline County administered & $\begin{array}{l}\text { Patient lived in county-administered (regions with populations of not less than } 150,000 \text { but not } \\
\text { more than 500,000, and possess thriving industrial and commercial development, adequate } \\
\text { financial resources for self-government, convenient transportation, and comprehensive public } \\
\text { facilities) = } 1 \text {; other = } 0\end{array}$ \\
\hline Town & $\begin{array}{l}\text { Patient lived in town (regions with populations of less than 150,000, and possess thriving } \\
\text { industrial and commercial development) }=1 \text {; other }=0\end{array}$ \\
\hline Village & $\begin{array}{l}\text { Patient lived in village (regions with populations of less than 150,000, and less economic } \\
\text { development) }=1 \text {; other }=0\end{array}$ \\
\hline
\end{tabular}

${ }^{a}$ US $\$ 1=$ NT\$33.4 in 1998.

${ }^{\mathrm{b}}$ Rural/urban stratify according to the Local Government Act.

the Poisson distribution is widely used. The second type of the regression model analysis is shown as follows:

$$
\begin{aligned}
\text { medical cost }_{i}= & \beta_{0}+\beta_{1} G_{i}+\beta_{2} A i+\beta_{3} W_{i}+\beta_{4} G E_{i} \\
& +\beta_{5} R_{i}+\beta_{6} P_{i}+\beta_{7} P_{i} \times G E_{i}+\varepsilon_{i}, \\
\text { length of stay } i= & \beta_{0}+\beta_{1} G_{i}+\beta_{2} A i+\beta_{3} W_{i} \\
& +\beta_{4} G E_{i}+\beta_{5} R_{i}+\beta_{6} P_{i} \\
& +\beta_{7} P_{i} \times G E_{i}+\varepsilon_{i} .
\end{aligned}
$$

The statistical package, STATA (STATA Corporation, version 11.0), was used for all of the statistical analyses undertaken in this study, with a two-side $P$ value of $\leq 0.1$ being considered to be statistically significant.

\section{Results}

3.1. Descriptive Statistics. The descriptive information on the sample is presented in Tables $2-4$. Table 2 showed the percentage of head injury that occurred and characterizes the potential confounders before and after law. Although our study sample revealed that the number of motorcyclists with head injuries increased from 609 to 645 , there was no significant difference in the incidence of head injury. The percentage of head injury in the pre- and postlaw period in our study sample was $0.0812 \%$ and $0.0813 \%$, respectively, which was very close to each other. However, the residents in the northern area had lower percentage of head injury after the law compared to the other areas. Moreover, the total 
Table 2: Percentage of head injury (1996 and 1998) in Taiwan.

\begin{tabular}{|c|c|c|c|c|}
\hline Variable & Before the helmet use law & After the helmet use law & $\%$ Change & $P$ value \\
\hline Percentage of head injur ${ }^{\mathrm{a}}$ & $0.0812 \%$ & $0.0813 \%$ & $0.1232 \%$ & \\
\hline Geographic locations & & & & $<0.0001$ \\
\hline North & $0.0461 \%$ & $0.0356 \%$ & $-22.8046 \%$ & \\
\hline Center & $0.0703 \%$ & $0.0796 \%$ & $13.1933 \%$ & \\
\hline South & $0.1058 \%$ & $0.1201 \%$ & $13.4863 \%$ & \\
\hline East & $0.0544 \%$ & $0.0705 \%$ & $29.6525 \%$ & \\
\hline Gender & & & & $<0.0001$ \\
\hline Male & $0.0949 \%$ & $0.1008 \%$ & $6.1654 \%$ & \\
\hline Female & $0.0688 \%$ & $0.0637 \%$ & $-7.4226 \%$ & \\
\hline Age & & & & $<0.001$ \\
\hline Children & $0.0106 \%$ & $0.0100 \%$ & $-6.0954 \%$ & \\
\hline Adult 15-24 & $0.1899 \%$ & $0.1603 \%$ & $-15.5572 \%$ & \\
\hline Adult 25-64 & $0.0797 \%$ & $0.0886 \%$ & $11.1168 \%$ & \\
\hline Elderly & $0.0797 \%$ & $0.0803 \%$ & $0.8056 \%$ & \\
\hline Rural/urban & & & & $<0.001$ \\
\hline Special municipality & $0.0506 \%$ & $0.0465 \%$ & $-8.2351 \%$ & \\
\hline City & $0.0607 \%$ & $0.0474 \%$ & $-21.9082 \%$ & \\
\hline County administered & $0.0724 \%$ & $0.0710 \%$ & $-1.8142 \%$ & \\
\hline Town & $0.1168 \%$ & $0.1719 \%$ & $47.2089 \%$ & \\
\hline Village & $0.1134 \%$ & $0.0919 \%$ & $-18.9339 \%$ & \\
\hline
\end{tabular}

Observations = 1,809,237 (before law in 1996 = 888,179; after law in 1998 = 921,058); number of head injury = 1,254 (before law = 609; after law = 645).

TABLE 3: Average medical cost per head injury in a motorcycle accident.

\begin{tabular}{|c|c|c|c|c|}
\hline Variable & Before the helmet use law & After the helmet use law & \% Change & $P$ value \\
\hline Medical cost & 21318.26 & 18866.76 & $-11.50 \%$ & \\
\hline Geographic locations & & & & 0.0289 \\
\hline North & 31007.97 & 23769.13 & $-23.35 \%$ & \\
\hline Center & 24298.08 & 15407.69 & $-36.59 \%$ & \\
\hline South & 18047.56 & 17821.99 & $-1.25 \%$ & \\
\hline East & 19979.75 & 21683.67 & $8.53 \%$ & \\
\hline Gender & & & & 0.5428 \\
\hline Male & 23921.35 & 20804.87 & $-13.03 \%$ & \\
\hline Female & 18071.60 & 16087.79 & $-10.98 \%$ & \\
\hline Age & & & & 0.0025 \\
\hline Children & 17020.90 & 9428.84 & $-44.60 \%$ & \\
\hline Adult 15-24 & 19818.66 & 16532.17 & $-16.58 \%$ & \\
\hline Adult 25-64 & 22781.54 & 21450.68 & $-5.84 \%$ & \\
\hline Elderly & 21183.06 & 12797.73 & $-39.59 \%$ & \\
\hline Rural/urban & & & & 0.0173 \\
\hline Special municipality & 29674.75 & 21949.89 & $-26.03 \%$ & \\
\hline City & 27034.62 & 19247.94 & $-28.80 \%$ & \\
\hline County administered & 16338.67 & 15193.83 & $-7.01 \%$ & \\
\hline Town & 24339.35 & 19275.41 & $-20.81 \%$ & \\
\hline Village & 23501.87 & 19282.52 & $-17.95 \%$ & \\
\hline
\end{tabular}

Observations $=1,254$.

Unit: NT \$, 1 US\$ = 33.4 NT\$ in 1998.

Medical costs due to head injuries are only for individuals that sustained a head injury in a motorcycle accident. 
TABLE 4: Average length of stay per head injury in a motorcycle accident.

\begin{tabular}{lccc}
\hline Variable & Before the helmet use law & After the helmet use law & Change \\
\hline Length of stay in hospitals & 6.78 & 5.52 & $-18.58 \%$ \\
\hline Geographic locations & & & $-15.85 \%$ \\
$\quad$ North & 7.76 & 6.53 & $-19.52 \%$ \\
Center & 6.66 & 5.36 & $-23.87 \%$ \\
South & 6.62 & 5.04 & $25.58 \%$ \\
East & 5.63 & 7.07 & $-17.11 \%$ \\
\hline Gender & & & $-21.13 \%$ \\
Male & 6.84 & 5.67 & 0.0049 \\
Female & 6.72 & 5.30 & $-24.10 \%$ \\
\hline Age & & & $-20.71 \%$ \\
Children & 6.10 & 4.63 & $-16.32 \%$ \\
Adult 15-24 & 5.94 & 4.71 & $-41.05 \%$ \\
Adult 25-64 & 7.29 & 6.10 & 0.0008 \\
Elderly & 8.60 & 5.07 & $-23.64 \%$ \\
\hline Rural/urban & & & $-26.46 \%$ \\
Special municipality & 8.46 & 6.46 & $-9.63 \%$ \\
$\quad$ City & 6.35 & 4.67 & $-24.86 \%$ \\
County administered & 5.61 & 5.07 & $-19.97 \%$ \\
Town & 7.24 & 5.44 & 0.1053 \\
Village & 7.06 & 5.65 & \\
\hline
\end{tabular}

Observations $=1,254$.

Unit: NT \$, 1 US\$ = 33.4 NT\$ in 1998.

Length of stay due to head injuries are only for individuals that sustained a head injury in a motorcycle accident.

TABLE 5: Logistic regression for the likelihood of sustaining a head injury in a motorcycle accident.

\begin{tabular}{|c|c|c|c|c|}
\hline Variable & Coefficient & Odds ratio & Standard error & $P$ value \\
\hline Intercept & $-8.1149^{* * *}$ & & 0.0983 & $<0.0001$ \\
\hline Policy interaction & $-0.2693^{* *}$ & 0.764 & 0.1057 & 0.0108 \\
\hline Policy*Center & $0.3664^{* *}$ & 1.443 & 0.1643 & 0.0258 \\
\hline Policy*South & $0.3881^{* * *}$ & 1.474 & 0.1334 & 0.0036 \\
\hline Policy*East & 0.5242 & 1.689 & 0.4110 & 0.2021 \\
\hline \multicolumn{5}{|l|}{ Geographic locations } \\
\hline Center & $0.3881^{* * *}$ & 1.474 & 0.1334 & 0.0036 \\
\hline South & 0.5242 & 1.689 & 0.4110 & 0.2021 \\
\hline East & 0.0561 & 1.058 & 0.3108 & 0.8568 \\
\hline \multicolumn{5}{|l|}{ (ref.: north) } \\
\hline Gender & $0.3301^{* * *}$ & 1.391 & 0.0572 & $<0.0001$ \\
\hline \multicolumn{5}{|l|}{ Age } \\
\hline Children & $-2.0731^{* * *}$ & 0.126 & 0.1647 & $<0.0001$ \\
\hline Adult 15-24 & $0.6227^{* * *}$ & 1.864 & 0.0606 & $<0.0001$ \\
\hline Elderly & -0.0431 & 0.958 & 0.1192 & 0.7178 \\
\hline (ref.: adult 25-64) & & & & \\
\hline \multicolumn{5}{|l|}{ Rural/urban } \\
\hline City & $-0.2614^{* *}$ & 0.770 & 0.1260 & 0.0380 \\
\hline County administered & $0.3246^{* * *}$ & 1.383 & 0.0947 & 0.0006 \\
\hline Town & $0.9101^{* * *}$ & 2.485 & 0.0927 & $<0.0001$ \\
\hline Village & $0.4130^{* * *}$ & 1.511 & 0.0891 & $<0.0001$ \\
\hline (ref.: special municipality) & & & & \\
\hline
\end{tabular}

$\overline{a * * *}$ Denotes significant at 0.01 level; ** denotes significant at 0.05 level; $*$ denotes significant at 0.1 level.

${ }^{\mathrm{b}}$ Reference groups: north, female, adult 25-64, special municipality, Policy* North.

Observations $=1809237$. 
TABLE 6: OLS regression for medical cost per head injury in a motorcycle accident.

\begin{tabular}{|c|c|c|c|}
\hline Variable & Coefficient $^{\mathrm{a}}$ & Standard error & $P$ value \\
\hline Intercept & $9.49096^{* * *}$ & 0.06281 & $<0.0001$ \\
\hline \multicolumn{4}{|l|}{ Policy interactions } \\
\hline Policy*Center & $-0.26555^{*}$ & 0.16026 & 0.0978 \\
\hline Policy*South & -0.10464 & 0.12879 & 0.4166 \\
\hline Policy* East & 0.26161 & 0.40985 & 0.5234 \\
\hline \multicolumn{4}{|l|}{ Geographic locations } \\
\hline Center & -0.00096 & 0.12829 & 0.9940 \\
\hline South & -0.06548 & 0.09799 & 0.5042 \\
\hline East & -0.30702 & 0.33084 & 0.3536 \\
\hline \multicolumn{4}{|l|}{ (ref.: north) } \\
\hline Gender & $0.13557^{* *}$ & 0.05293 & 0.0106 \\
\hline \multicolumn{4}{|l|}{ Age } \\
\hline Children & $-0.32607^{* *}$ & 0.14953 & 0.0294 \\
\hline Adult 15-24 & $-0.21468^{* * *}$ & 0.05513 & 0.0001 \\
\hline Elderly & -0.10688 & 0.10941 & 0.3288 \\
\hline \multicolumn{4}{|l|}{ (ref.: adult 25-64) } \\
\hline \multicolumn{4}{|l|}{ Rural/urban } \\
\hline City & -0.02904 & 0.12142 & 0.8110 \\
\hline County administered & -0.11522 & 0.08924 & 0.1969 \\
\hline Town & -0.01480 & 0.08723 & 0.8653 \\
\hline Village & 0.00583 & 0.08519 & 0.9454 \\
\hline (ref.: special municipality) & & & \\
\hline
\end{tabular}

medical cost and the length of stay incurred were much lower after the implementation of law.

Table 3 indicated that the total medical cost incurred was also greater before law than after law (NT\$21318.3 versus NT\$18866.8; US\$638 versus US\$564.8), declined by $11.5 \%$ after law. There was a reduction of NT $\$ 2,451.50$ in overall medical cost attributable to head injuries following the implementation of the law, with only the Eastern regions showing higher average medical cost on such injuries. Furthermore, medical cost of head injuries for children and the elderly decreased dramatically after the law. Similarly, the average number of length of stay before law (6.78) was also higher than the average after law (5.52) in Table 4. The average hospital length of stay attributable to head injury decreased by 1.26 days (18.58 percent) and only the length of stay in the Eastern region increased following the introduction of the law. The average length of stay for the elderly also decreased by $41.05 \%$ after the law.

3.2. Logistic Regression Result. Table 5 shows the factors associated with the likelihood of head injury. The two interaction variables (Center and South) were statistically significant and positively related to the likelihood of having head injury. This result indicated that motorcyclists in the central and southern regions were more likely to incur head injury than northern motorcyclist after the introduction of the law. In other words, the implementation of the helmet use law did not decrease the incident of head injury in the central and southern regions. The positive coefficient of gender meant that male was more likely to have head injury than female. Compared to adults aged 25-64, children were less likely to incur head injury and adults aged 15-24 were more likely to incur head injury. Motorcyclists in the rural areas were more likely to have head injury than urban motorcyclists.

3.3. Ordinary Least Squares Regression and Poisson Regression Results. The relationship between medical cost attributable to head injuries and the implementation of the law on motorcycle helmet usage is shown in Table 6. Significantly less medical cost attributable to motorcycle head injuries is found for the variables of geographic location, gender, and age. Motorcyclists in the central geographic region had lower average medical costs compared to those in the northern region after the implementation of the law. Males tended to have higher medical cost than females. Children and adults aged 15-24 were likely to have less medical cost than adults aged $25-64$.

As can be seen in Table 7, the interaction coefficients were strongly significant and negative in the regression on hospital length of stay, indicating that length of stay in hospitals attributable to head injury was reduced significantly after 
TABLE 7: Poisson regression for length of stay per head injury in a motorcycle accident.

\begin{tabular}{|c|c|c|c|}
\hline Variable & Coefficient $^{\mathrm{a}}$ & Standard error & $P$ value \\
\hline Intercept & $2.0449^{* * *}$ & 0.0265 & $<0.0001$ \\
\hline Policy interactions & -0.0114 & 0.0407 & 0.7797 \\
\hline Policy* Center & $-0.2175^{* * *}$ & 0.0708 & 0.0021 \\
\hline Policy*South & $-0.2780^{* * *}$ & 0.0567 & $<0.0001$ \\
\hline Policy*East & $0.3236^{*}$ & 0.1840 & 0.0785 \\
\hline \multicolumn{4}{|l|}{ Geographic locations } \\
\hline Center & 0.0383 & 0.0555 & 0.4897 \\
\hline South & -0.0161 & 0.0424 & 0.7036 \\
\hline East & -0.2333 & 0.1538 & 0.1293 \\
\hline \multicolumn{4}{|l|}{ (ref.: north) } \\
\hline Gender & 0.0123 & 0.0238 & 0.6056 \\
\hline \multicolumn{4}{|l|}{ Age } \\
\hline Children & $-0.2245^{* * *}$ & 0.0709 & 0.0015 \\
\hline Adult 15-24 & $-0.2330^{* * *}$ & 0.0253 & $<0.0001$ \\
\hline Elderly & -0.0042 & 0.0471 & 0.9292 \\
\hline \multicolumn{4}{|l|}{ (ref.: adult 25-64) } \\
\hline \multicolumn{4}{|l|}{ Rural/urban } \\
\hline City & $-0.1608^{* * *}$ & 0.0567 & 0.0045 \\
\hline County administered & $-0.2153^{* * *}$ & 0.0411 & $<0.0001$ \\
\hline Town & -0.0525 & 0.0388 & 0.1756 \\
\hline Village & -0.0141 & 0.0375 & 0.7079 \\
\hline (ref.: special municipality) & & & \\
\hline
\end{tabular}

a*** Denotes significant at 0.01 level; ** denotes significant at 0.05 level; ${ }^{*}$ denotes significant at 0.1 level.

${ }^{b}$ Reference groups: north, female, adult 25-64, special municipality, Policy* North.

Observations $=1,254$.

the implementation of the motorcycle helmet use law for central and southern motorcyclists. Only motorcyclists in the eastern region increased hospital length of stay after the law. Children and adults aged 15-24 were found to have much shorter length of stay than adults aged 25-64. As compared to the metropolitan cities, the smaller cities were shown to have much shorter periods of hospital length of stay.

\section{Discussion}

Studies undertaken in many Western countries have found that the introduction of laws mandating the use of motorcycle helmets can effectively reduce both injuries and fatalities $[2-5,7,13-16]$.

Statistics provided by the Ministry of the Transportation and Communications in Taiwan also reveal a significant fall in motorcycle traffic fatalities, from 1,318 in 1996, to 1,042 in 1998 (a 20.9 percent reduction), following the introduction of the motorcycle helmet use law. Furthermore, this significant reduction in the total number of motorcycle fatalities has been achieved despite the steady increase in the total number of motorcycles, from 9.28 million in 1996, to 10.52 million in 1998 [17]. Two studies conducted in Taiwan reinforced that after the implementation of helmet use law, riders were at lower risk of head injury and fatalities $[11,12]$.

Although a number of studies have emerged suggesting decreased risks of head injury and fatalities associated with the passage of helmet use law, no nationwide populationbased study has ever been undertaken investigating the impact of the motorcycle helmet usage law on the likelihood of head injury and the associated medical care utilization relating to incidences of head injury. This study is the first of its kind worldwide to use a selected population-based data to explore the association between the motorcycle helmet use law and the associated medical utilization.

Our empirical results revealed that following the 1997 implementation of the motorcycle helmet use law, significant reductions in the northern region have been achieved, not only in the probability of head injury, but also in the medical cost and hospital length of stay attributable to such injuries. The probability of motorcycle head injury has been reduced by 22.8 percent, whilst medical cost and hospital length of stay are down by around 23.5 percent and 15.8 percent, respectively. However, regional differences do exist. The results showed that non-northern motorcyclists increased their probability of head injury after the law. Nevertheless, except eastern region where most of the mountains were located and were less developed and populated than the other regions, central and southern regions had lower medical cost and hospital length of stay. As compared to the most populated area of northern Taiwan, other regions in Taiwan seem to have much higher incidence of motorcycle head injuries in the logistic regression. We surmise that this is because, unlike 
the northern area, the limited number of police in other areas tends to hamper the enforcement of motorcycle helmet use law, which thereby contributes to higher numbers of head injuries/fatalities attributable to motorcycle accidents. Nevertheless, medical cost and hospital length of stay of head injury were reduced significantly in the central and southern regions compared to the northern region after the implementation of motorcycle helmet use law in the OLS and Poisson regression results. In other words, although the likelihood of head injury incidence was not reduced after the law, the severity of head injury incidences was reduced significantly after the law.

This finding is consistent with the previous study [12]. The evidence provided by this study supports the hypothesis that the implementation of the law mandating the use of motorcycle helmets has resulted in the effective reduction of severe head injuries and fatalities in Taiwan attributable to motorcycle accidents. Additionally, we also find that the control variables, including gender, age, geographic location, and rural/urban, areas all have significant impacts on the incidence and the associated medical cost and hospital length of stay of motorcycle head injuries.

Two limitations to this study need to be addressed. First, being an administrative claims dataset, it lacks information on some demographic characteristics such as education and income. Second, other factors, such as weather conditions and wearing helmet or not which might contribute to incidence of head injury, are also not available in this database. Accounting for these factors would enable more refined conclusions and,therefore, targeted policy initiatives.

Nevertheless, incidences of motorcycle head injury and the resultant mortality and morbidity rates impose serious socioeconomic costs, in terms of lost working time and income, on both the victims and their families. Our results indicate that medical cost and hospital length of stay have been reduced in Taiwan due to the reduction in the severity of motorcycle head injuries. Thus, with the introduction of the motorcycle helmet use law having had a demonstrably positive influence on motorcycle head injuries and fatalities, significant savings are clearly being achieved, not only in terms of economic and social costs, but also with regard to medical cost and medical resources.

This should be reassuring news for the authorities in Taiwan, proving that their efforts to promote motorcycle helmet usage are delivering positive results. Such an accomplishment may also provide reassurance to other developing countries in which motorcycles tend to be the primary means of transport, such that they may also consider the introduction of laws mandating the use of motorcycle helmets.

\section{Acknowledgments}

This study was supported by the National Science Council of Taiwan (NSC 96-2416-H-305-002-MY3). This study is based in part on data from the National Health Insurance Research Database provided by the Bureau of National Health Insurance, Department of Health, Taiwan and managed by the National Health Research Institutes.

\section{References}

[1] Ministry of Interior Statistical Reports, 2008, Department of Statistics, Ministry of Interior, Republic of China.

[2] J. F. Kraus, C. Peek, D. L. McArthur, and A. Williams, "The effect of the 1992 California motorcycle helmet use law on motorcycle crash fatalities and injuries," Journal of the American Medical Association, vol. 272, no. 19, pp. 1506-1511, 1994.

[3] F. Servadei, C. Begliomini, E. Gardini, M. Giustini, F. Taggi, and J. Kraus, "Effect of Italy's motorcycle helmet law on traumatic brain injuries," Injury Prevention, vol. 9, no. 3, pp. 257260, 2003.

[4] M. Ichikawa, W. Chadbunchachai, and E. Marui, "Effect of the helmet act for motorcyclists in Thailand," Accident Analysis and Prevention, vol. 35, no. 2, pp. 183-189, 2003.

[5] S. H. Keng, "Helmet use and motorcycle fatalities in Taiwan," Accident Analysis and Prevention, vol. 37, no. 2, pp. 349-355, 2005.

[6] D. J. Houston and L. E. Richardson, "Motorcycle safety and the repeal of universal helmet laws," American Journal of Public Health, vol. 97, no. 11, pp. 2063-2069, 2007.

[7] K. J. Mertz and H. B. Weiss, "Changes in motorcycle-related head injury deaths, hospitalizations, and hospital charges following repeal of Pennsylvania's mandatory motorcycle helmet law," American Journal of Public Health, vol. 98, no. 8, pp. 1464-1467, 2008.

[8] A. J. Derrick and L. D. Faucher, "Motorcycle helmets and rider safety: a legislative crisis," Journal of Public Health Policy, vol. 30, no. 2, pp. 226-242, 2009.

[9] M. T. French, G. Gumus, and J. F. Homer, "Public policies and motorcycle safety," Journal of Health Economics, vol. 28, no. 4, pp. 831-838, 2009.

[10] H. Y. Lee, Y. H. Chen, W. T. Chiu, J. S. Hwang, and J. D. Wang, "Quality-adjusted life-years and helmet use among motorcyclists sustaining head injuries," American Journal of Public Health, vol. 100, no. 1, pp. 165-170, 2010.

[11] M. C. Tsai and D. Hemenway, "Effect of the mandatory helmet law in Taiwan," Injury Prevention, vol. 5, no. 4, pp. 290-291, 1999.

[12] W. T. Chiu, C. Y. Kuo, C. C. Hung, and M. Chen, "The effect of the Taiwan motorcycle helmet use law on head injuries," American Journal of Public Health, vol. 90, no. 5, pp. 793-796, 2000.

[13] N. S. Fleming and E. R. Becker, "The impact of the Texas 1989 motorcycle helmet law on total and head-related fatalities, severe injuries, and overall injuries," Medical Care, vol. 30, no. 9, pp. 832-845, 1992.

[14] R. L. Muelleman, E. J. Mlinek, and P. E. Collicott, "Motorcycle crash injuries and costs: effect of a reenacted comprehensive helmet use law," Annals of Emergency Medicine, vol. 21, no. 3, pp. 266-272, 1992.

[15] C. C. Branas and M. M. Knudson, "Helmet laws and motorcycle rider death rates," Accident Analysis and Prevention, vol. 33, no. 5, pp. 641-648, 2001.

[16] J. Mayrose, "The effects of a mandatory motorcycle helmet law on helmet use and injury patterns among motorcyclist fatalities," Journal of Safety Research, vol. 39, no. 4, pp. 429432, 2008.

[17] Ministry of Transportation and Communications, "Monthly statistics of transportation and communications," 2007, Department of Statistics, Ministry of Transportation and Communications, Republic of China. 


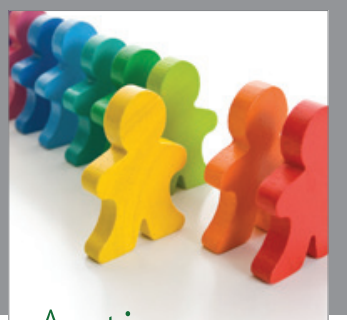

Autism

Research and Treatment
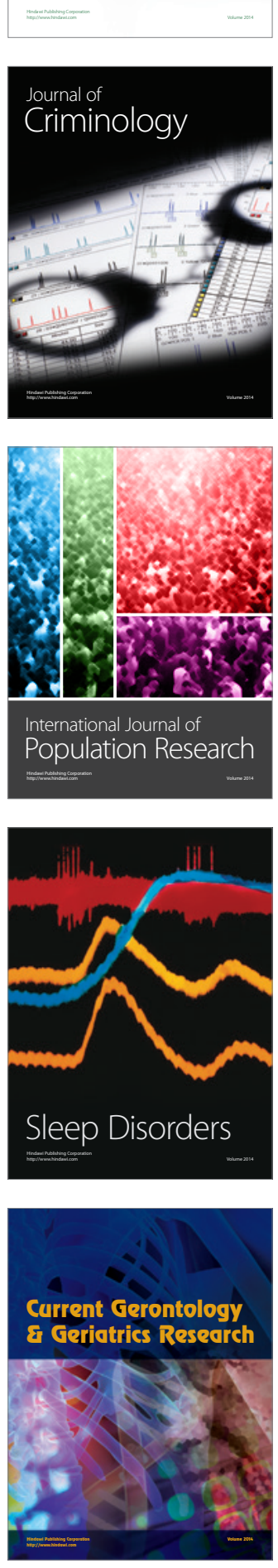
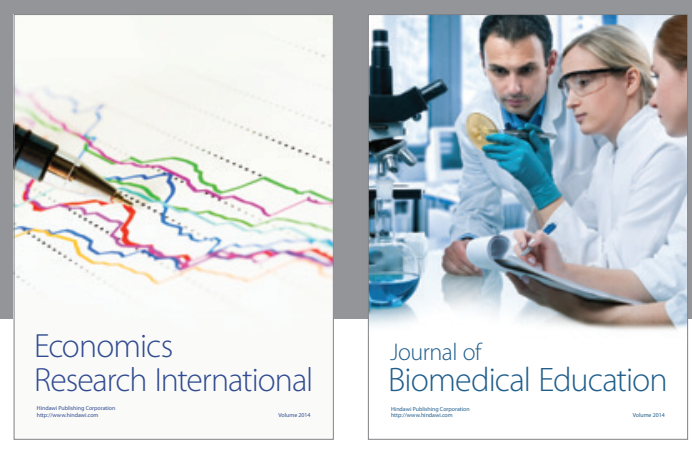

Journal of

Biomedical Education

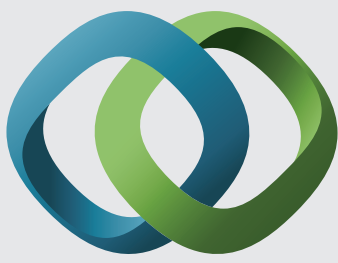

\section{Hindawi}

Submit your manuscripts at

http://www.hindawi.com
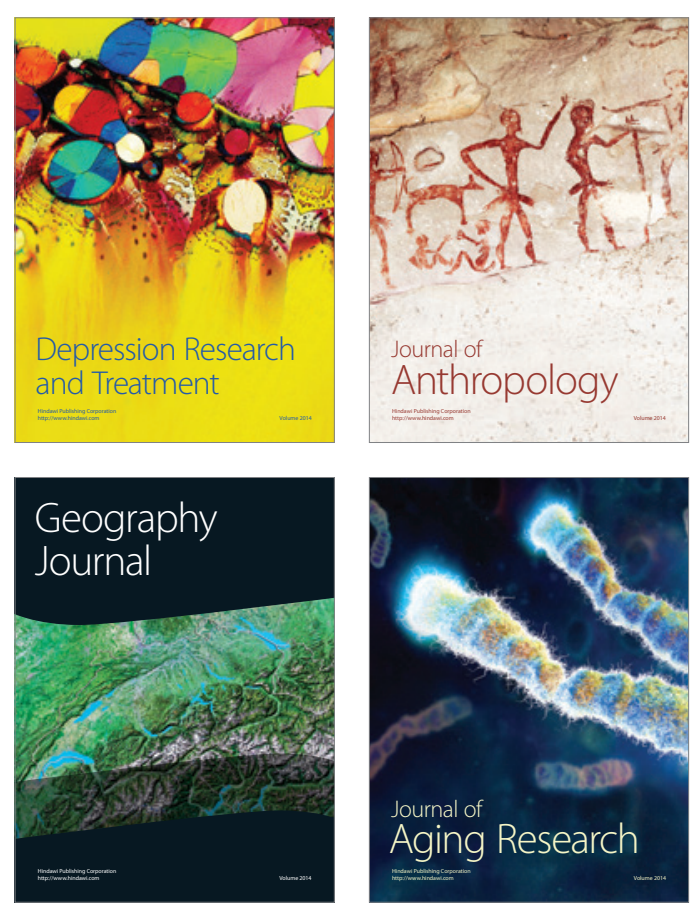

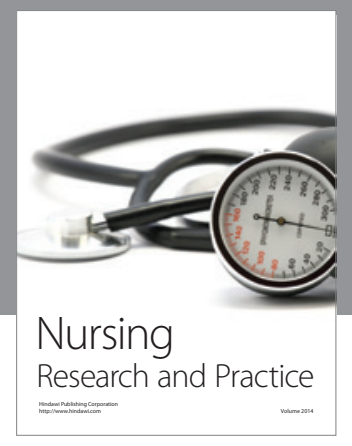

Nursing

Research and Practice

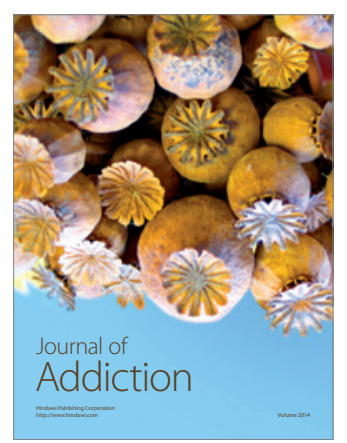

Child Development

Research

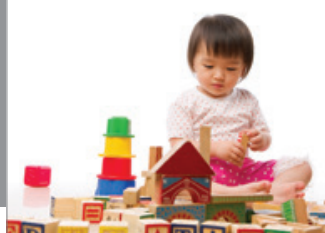

迥
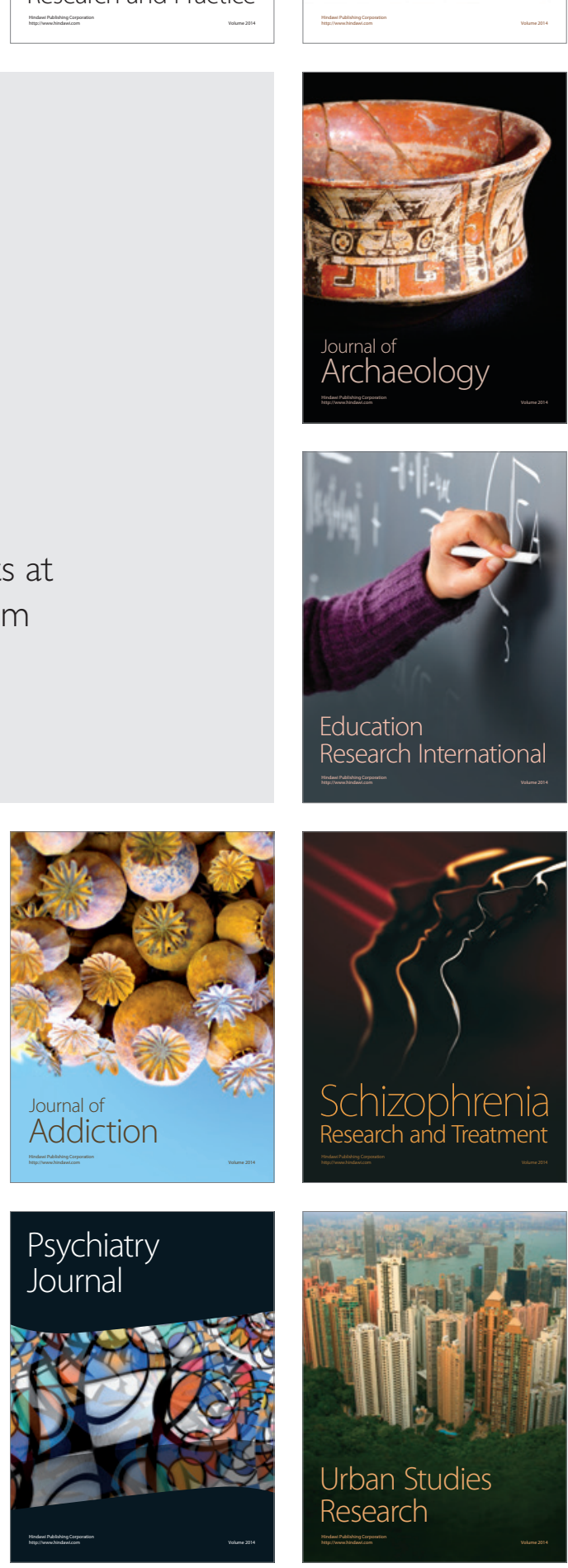